\title{
Research on Comprehensive Evaluation Index System of Traffic Infrastructure Construction
}

\author{
Zhi-yu Chen, a , Jing Liü, b \\ ${ }^{1}$ Research Institute of Highway Ministry of Transport, 100088,Beijing China \\ achenkitty7799@126.com
}

\begin{abstract}
Keywords: Traffic Infrastructure; Evaluating Indicator; Quality Engineering; AHP
Abstract. In order to accelerate the modern engineering management, promote the transformation and upgrading of highway and waterway engineering construction and development, improve the quality, safety and operation service level of highway and waterway engineering, the article sets up an evaluation index system on seven promotion such as engineering design level, management level, technological innovation ability, quality level, safety level, green environment level and soft power of quality engineering. This article combines Delphy Method and analytic hierarchy process (AHP) to analyze the weight of the index, select the project to carry on the empirical evaluation. Finally, this article examines the scientificity and rationality of the evaluation index system.
\end{abstract}

\section{Introduction}

Since the 80s of the last century, the construction of transportation infrastructure in China has developed rapidly for more than 30 years. China has built up a number of engineering Cross Sea Bridges, long tunnels and large coastal port projects which has important influence in the world. Meanwhile, accumulated a lot of experience of quality and safety management of engineering construction, It promotes the quality and safety management of the construction of highway water transportation project in China.

This article is based on the major special activities organized by the Ministry of transportation and transportation which named "Building the quality project of highway water transportation", for improving the management level, improving the quality and safety management level of traffic base design, strengthening innovation to drive development ability, study on the evaluation index system of "quality engineering". By characterizing the characteristics of "quality engineering" in all aspects and its interrelated indicators, this article constitutes an organic whole with internal structure to set up a series of index systems to evaluate the quality engineering, to breakthrough and innovation of the highway water transportation in the fields of technology, management, standards and so on.

\section{Evaluation Target}

In December 26th, 2016, the Ministry of transportation issued "guidance on building the quality of highway water quality project", it further interprets the connotation of quality engineering:

Construction idea: It embodies the concept of people-oriented, essential safety, life cycle management and value engineering.

Management measures: It embodies the guidance of lean construction, emphasizes the implementation of responsibility and integrity, and deepens humanism, specialization, standardization, information and refinement.

Technical Progress: It embodies technological innovation and breakthroughs, advanced technology theories and methods can be widely applied, also includs the exploration and improvement of advanced and applicable new technologies, new processes, new materials, new equipment new standards and so on.

Quality Assurance: It is based on the durability of the project, reflecting the coordination of construction, operation and maintenance, harmony between engineering and natural humanities, the 
balanced development of engineering entity quality, function quality, appearance quality and service quality.

Security Management: It aims at the pursuit of the essential safety of engineering and risk control, and promotes the coordinated development of engineering structure safety, construction safety and use safety.

Engineering Construction: Insisting on Sustainable Development, it has achieved remarkable achievements in ecological environmental protection, resource conservation, energy conservation, emission reduction and so on.

According to the connotation of quality engineering and the main task of building quality engineering, this paper divides the evaluation content into seven parts: engineering design, engineering management, technological innovation, construction quality, safety guarantee, greens environmental protection and soft power.

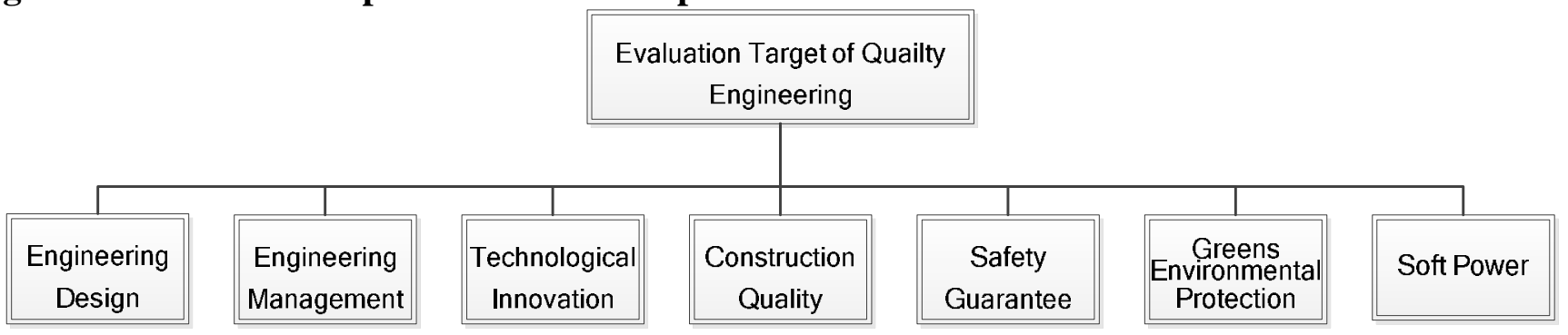

\section{Figure 1 Evaluation Target of Quailty Engineering}

\section{Construction of evaluation index system}

1) Building the hierarchical structure model

Building a hierarchical analysis structure model, AHP can be used to solve the related problems in the field of economic management. This level is divided into three layers: the target layer, the standard layer and the index layer.

$\Phi$ The target layer (I): It includes the target and the result of the target. There is only one element in this layer.

2 The standard layer (II): It is an intermediate link to achieve the goal. It can be divided into several levels. For example, the standard layer I, the standard layer II and so on.

3 The index layer (III): The options and targets for achieving goals and guidelines

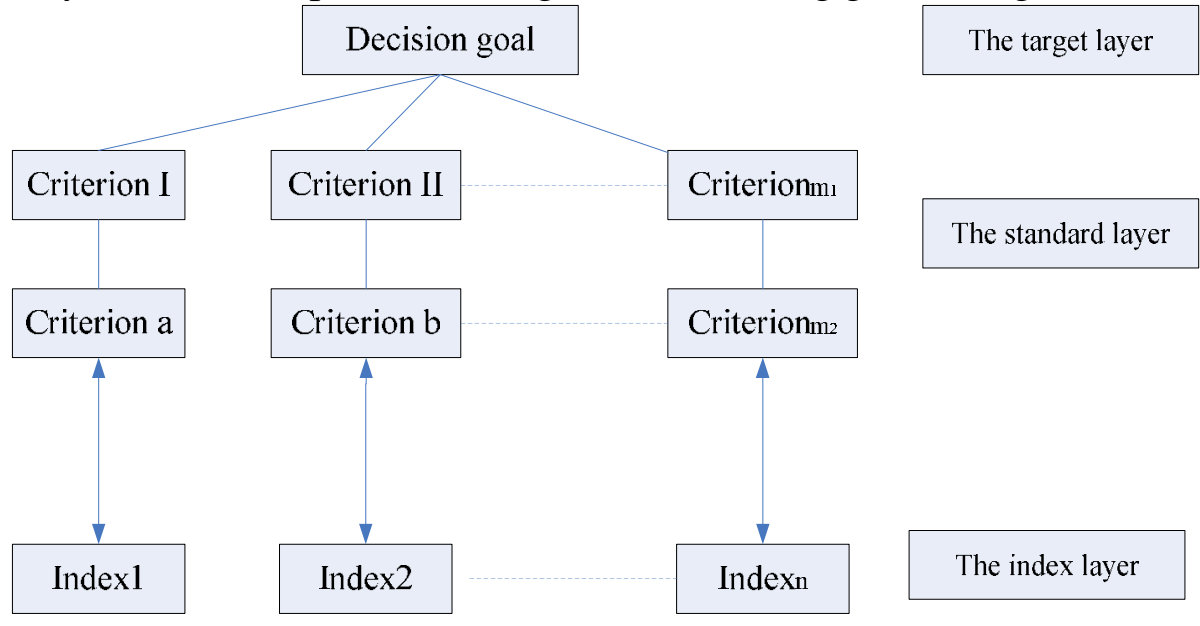

Figure 2 Hierarchical structure diagram

The number of layers in hierarchical is related to the complexity and exhaustion of the analytical problems. If you want to analyze the problem in detail, you need to build a good hierarchy.

\section{2) Constructing the judgment matrix of comparison}

For the n elements, The judgment matrix of the comparison is $C=\left(C_{i j}\right)_{n \times n}$, The judgment matrix of the structure is as follows: 


\begin{tabular}{c|cccc}
$B_{k}$ & $C_{1}$ & $C_{2}$ & $\ldots$ & $C_{n}$ \\
\hline$C_{1}$ & $C_{11}$ & $C_{12}$ & $\ldots$ & $C_{1 n}$ \\
$C_{2}$ & $C_{21}$ & $C_{22}$ & $\ldots$ & $C_{2 n}$ \\
$\ldots$ & $\ldots$ & $\ldots$ & $\ldots$ & $\ldots$ \\
$C_{n}$ & $C_{n 1}$ & $C_{n 2}$ & $\ldots$ & $C_{n n}$
\end{tabular}

\section{3) Checking the consistency of judgment matrix}

The consistency test is to test the coordination between the elements' importance and avoid the conflicting phenomena between the elements. In the AHP method, lead into the negative mean value of the other characteristic roots outside the maximum eigenvalue of the matrix, use this as an indicator of the deviation of the judgment matrix from the consistency.

$$
C I=\frac{\lambda_{\max }-n}{n-1}
$$

To test the consistency of decision makers' judgement thinking, the smaller the CI value, it shows that the better the consistency of the judgment matrix is better. The greater the CI value, the greater the degree of deviation from the complete consistency of the judgment matrix.

\section{4) Hierarchical single order}

The relative importance of a factor at a certain level relative to a certain factor in the previous level, it can be reduced to the maximum characteristic root and the eigenvector problem of the calculation judgment matrix.

$\Phi$ Calculation of the product of each element in a judgement matrix $M_{i}$.

$$
M_{i}=\prod_{j=1}^{n} a_{i j} \quad \mathrm{i}=1,2, \ldots, \mathrm{n}
$$

๑Calculation of the n square root $\bar{W}_{i}$ of $M_{i}$

$\overline{W_{i}}=\sqrt[n]{M_{i}}$

(3) Normalization of vector $\bar{W}=\left[\overline{W_{1}}, \overline{W_{2}}, \ldots, \overline{W_{n}}\right]^{T}$

Then $W=\left[W_{1}, W_{2}, \ldots, W_{n}\right]^{T}$ is the eigenvector.

$\oplus$ The maximum eigenvalue of the calculation judgment matrix: $\lambda_{\max }$

$$
\lambda_{\max }=\sum_{i=1}^{n} \frac{(A W)_{i}}{n W_{i}}
$$

\section{5) Total ranking of layers}

According to the hierarchical structure, a layer by layer calculation should be carried out from the upper layer of the upper layer. Thus, the ranking values of the lowest level relative to the relative importance of the highest level can be calculated.

6) Make the corresponding decision based on the results of the previous steps

Finally through consistency test, it is concluded that the weight of quality engineering evaluation index. 


\section{Evaluation index system}

This paper, through extensive social investigation, consulted experts and consulted relevant documents, decomposed 7 target level indicators into 27 two level indicators, and then decomposed 27 two level indexes into 80 specific indexes. As follows:

Table1 Weight of Quality Engineering Evaluation Index

\begin{tabular}{|c|c|c|}
\hline $\begin{array}{l}\text { The Target } \\
\text { Layer (I) }\end{array}$ & The standard layer (II) & The index layer (III) \\
\hline \multirow{16}{*}{$\begin{array}{l}\text { Design Level } A_{1} \\
\quad(0.2939)\end{array}$} & \multirow{5}{*}{$\begin{array}{l}\text { System Design } B_{11} \\
(0.4428)\end{array}$} & Life Cycle Cost Concept $C_{111}(0.2469)$ \\
\hline & & Integration Concept of Building and Raising $\mathrm{C}_{112}(0.2922)$ \\
\hline & & Durability Guarantee $\mathrm{C}_{113}(0.1401)$ \\
\hline & & Standardization and Generalization Design $\mathrm{C}_{114}(0.1768)$ \\
\hline & & Security Risk Protection $\mathrm{C}_{115}(0.1440)$ \\
\hline & \multirow{2}{*}{$\begin{array}{c}\text { The concept of Ecological } \\
\text { Environment Protection } \\
\qquad \mathrm{B}_{12} \\
(0.1341)\end{array}$} & The Use of Ecological Protection Technology $C_{121}(0.5000)$ \\
\hline & & $\begin{array}{l}\text { Location Rationality of Ecological Line Selection } \mathrm{C}_{122} \\
\qquad(0.5000)\end{array}$ \\
\hline & \multirow{3}{*}{$\begin{array}{l}\text { Engineering Aesthetics } \mathrm{B}_{13} \\
\qquad(0.1028)\end{array}$} & The Beauty of Vegetation in the Road Area $C_{131}(0.3333)$ \\
\hline & & $\begin{array}{l}\text { The Degree of Fusion with the Natural Environment } \mathrm{C}_{132} \\
\qquad(0.3333)\end{array}$ \\
\hline & & $\begin{array}{c}\text { Cultural Fusion Degree of Regional Humanistic } \\
\text { Characteristics } C_{133}(0.3333)\end{array}$ \\
\hline & \multirow{3}{*}{$\begin{array}{l}\text { Humanization Design } \mathrm{B}_{14} \\
\qquad(0.1999)\end{array}$} & Perfection Degree of the Service Area $C_{141}(0.5693)$ \\
\hline & & Supporting Facilities of the Road $\mathrm{C}_{142}(0.2557)$ \\
\hline & & Residents' Satisfaction along the Road $\mathrm{C}_{143}(0.1750)$ \\
\hline & \multirow{3}{*}{$\begin{array}{l}\text { Service Level } \mathrm{B}_{15} \\
\quad(0.1204)\end{array}$} & Speciality and Quantity of the Service Person $C_{151}(0.4242)$ \\
\hline & & Satisfaction Survey $\mathrm{C}_{152}(0.1515)$ \\
\hline & & Dynamic Design and Optimal Design $\mathrm{C}_{153}(0.4242)$ \\
\hline \multirow{12}{*}{$\begin{array}{l}\text { Management } \\
\text { Level } A_{2} \\
(0.1725)\end{array}$} & \multirow{2}{*}{$\begin{array}{c}\text { Specialization of } \\
\text { Management } \mathrm{B}_{21}(0.3976)\end{array}$} & Professional Management Ability $\mathrm{C}_{211}(0.6667)$ \\
\hline & & The Degree of Integrity of Management System $C_{212}(0.3333)$ \\
\hline & \multirow{2}{*}{$\begin{array}{c}\text { Standardization of } \\
\text { Construction } \mathrm{B}_{22}(0.3005)\end{array}$} & Degree of Process Standardization $\mathrm{C}_{221}(0.5000)$ \\
\hline & & Factory Production and Assembly Construction $\mathrm{C}_{222}(0.5000)$ \\
\hline & \multirow{2}{*}{$\begin{array}{c}\text { Refinement of } \\
\left.\text { Management } \mathrm{B}_{23} 0.2622\right)\end{array}$} & Refinement of Management of Construction $\mathrm{C}_{231}(0.5000)$ \\
\hline & & Standardization of Management System $\mathrm{C}_{232}(0.5000)$ \\
\hline & \multirow{2}{*}{$\begin{array}{c}\text { Informatization of } \\
\text { Management } \mathrm{B}_{24}(0.0304)\end{array}$} & Informatization of Management of Engineering $\mathrm{C}_{241}(0.7500)$ \\
\hline & & Coverage of BIM C $242(0.2500)$ \\
\hline & \multirow{4}{*}{$\begin{array}{c}\text { Normalization of Group } \\
\text { Management } \mathrm{B}_{25} \\
(0.0093)\end{array}$} & $\begin{array}{l}\text { The Perfect Situation of the Management System of the } \\
\text { Construction Team } C_{251}(0.5699)\end{array}$ \\
\hline & & The Construction of Group Culture $\mathrm{C}_{252}(0.1616)$ \\
\hline & & $\begin{array}{l}\text { The Percentage of Real Name Management for Group Staff } \\
\qquad \mathrm{C}_{253}(0.2332)\end{array}$ \\
\hline & & The Extension of the First System of Group $\mathrm{C}_{254}(0.0353)$ \\
\hline \multirow{8}{*}{$\begin{array}{l}\text { Technological } \\
\text { Innovation } A_{3} \\
\quad(0.6667)\end{array}$} & \multirow{4}{*}{$\begin{array}{l}\text { Application of New } \\
\text { TechnologyB }{ }_{31} \\
(0.6667)\end{array}$} & Application of New Craftwork $\mathrm{C}_{311}(0.2500)$ \\
\hline & & Application of New Technology $\mathrm{C}_{312}(0.2500)$ \\
\hline & & Application of New Equipment $\mathrm{C}_{313}(0.2500)$ \\
\hline & & Application of New Materials $\mathrm{C}_{314}(0.2500)$ \\
\hline & \multirow{4}{*}{$\begin{array}{l}\text { Achievements of Scientific } \\
\text { Research and Innovation } \\
\mathrm{B}_{32}(0.3333)\end{array}$} & Number of Technological Innovation Results $C_{321}(0.1581)$ \\
\hline & & $\begin{array}{l}\text { The Situation of Management and Institutional Innovation } \\
\qquad \mathrm{C}_{322}(0.2376)\end{array}$ \\
\hline & & $\begin{array}{l}\text { Situation of Major Technical Problems Breakthrough } \mathrm{C}_{323} \\
(0.5770)\end{array}$ \\
\hline & & $\begin{array}{l}\text { Situation of Group Innovation and Micro Innovation } \mathrm{C}_{324} \\
\qquad(0.0273)\end{array}$ \\
\hline
\end{tabular}




\begin{tabular}{|c|c|c|}
\hline \multirow{17}{*}{$\begin{array}{l}\text { Quality Level } A_{4} \\
\quad(0.2703)\end{array}$} & \multirow{2}{*}{$\begin{array}{l}\text { Quality Management } \\
\text { System } \mathrm{B}_{41} \\
(0.4151)\end{array}$} & Implementation Degree of Key Person's Duty $\mathrm{C}_{411}(0.5000)$ \\
\hline & & $\begin{array}{c}\text { Implementation Degree of Quality Responsibility Tenure } \\
\text { System } \mathrm{C}_{412}(0.5000)\end{array}$ \\
\hline & \multirow{2}{*}{$\begin{array}{c}\text { Quality Risk Prevention } \\
\text { and Control System } B_{42} \\
(0.1562)\end{array}$} & Quality Risk Analysis and Evaluation $\mathrm{C}_{421}(0.3333)$ \\
\hline & & $\begin{array}{l}\text { The Implementation Degree of the Construction Scheme } \\
\text { Demonstration Review System } \mathrm{C}_{422}(0.6667)\end{array}$ \\
\hline & \multirow{6}{*}{$\begin{array}{c}\text { Process Quality Control } \\
\mathrm{B}_{43} \\
(0.2967)\end{array}$} & $\begin{array}{l}\text { The Implementation Degree of the Three Inspection System } \\
\qquad \mathrm{C}_{431}(0.4042)\end{array}$ \\
\hline & & Control of General Quality Disease $\mathrm{C}_{432}(0.3231)$ \\
\hline & & Quality Forming Process Can be Traced $\mathrm{C}_{433}(0.1308)$ \\
\hline & & First Piece of Production $\mathrm{C}_{434}(0.0768)$ \\
\hline & & Time Limit and Process Control $\mathrm{C}_{435}(0.0575)$ \\
\hline & & Construction Information Management $\mathrm{C}_{436}(0.0075)$ \\
\hline & \multirow{5}{*}{$\begin{array}{c}\text { Durability Safeguard } \\
\text { Measures } \mathrm{B}_{44} \\
(0.0394)\end{array}$} & $\begin{array}{l}\text { Improvement of Durability Construction Technology } \mathrm{C}_{441} \\
(0.1693)\end{array}$ \\
\hline & & The Standard of Durability Control Index $\mathrm{C}_{442}(0.3545)$ \\
\hline & & Quality Inspection of Key Structure $\mathrm{C}_{443}(0.3545)$ \\
\hline & & Quality Inspection of Concealed Engineering $\mathrm{C}_{444}(0.0847)$ \\
\hline & & Quality Inspection of Important Materials $\mathrm{C}_{445}(0.0370)$ \\
\hline & \multirow{2}{*}{$\begin{array}{c}\text { Construction Quality } \mathrm{B}_{45} \\
(0.0926)\end{array}$} & Physical Quality $\mathrm{C}_{451}(0.7500)$ \\
\hline & & Appearance Quality $\mathrm{C}_{452}(0.2500)$ \\
\hline \multirow{8}{*}{$\begin{array}{c}\text { Security Level } \\
\mathbf{A}_{5} \\
(\mathbf{0 . 0 9 2 5})\end{array}$} & \multirow{3}{*}{$\begin{array}{c}\text { Safety of Construction } \\
\text { Process } B_{51} \\
(0.4374)\end{array}$} & Safety Construction Site $\mathrm{C}_{511}(0.6105)$ \\
\hline & & Safety Standardization Construction $\mathrm{C}_{512}(0.1695)$ \\
\hline & & Dual Prevention System $C_{513}(0.2200)$ \\
\hline & \multirow{2}{*}{$\begin{array}{c}\text { Structural Safety } \mathrm{B}_{52} \\
(0.4165)\end{array}$} & Key Index of Structural Safety $C_{521}(0.5000)$ \\
\hline & & Intelligent Early Warning $\mathrm{C}_{522}(0.5000)$ \\
\hline & \multirow{3}{*}{$\begin{array}{l}\text { Security Service Level } B_{53} \\
\qquad(0.1461)\end{array}$} & Integrity of Safety Facilities $\mathrm{C}_{531}(0.3333)$ \\
\hline & & $\begin{array}{l}\text { Safe Operation Monitoring and Early Warning System } \mathrm{C}_{532} \\
(0.3333)\end{array}$ \\
\hline & & $\begin{array}{c}\text { Engineering Inspections for Risk and Emergency Treatment } \\
\text { Measures } \mathrm{C}_{533}(0.3333)\end{array}$ \\
\hline \multirow{10}{*}{$\begin{array}{c}\text { Environmental } \\
\text { Protection Level } \\
\mathbf{A}_{6} \\
(\mathbf{0 . 0 6 2 1})\end{array}$} & \multirow{4}{*}{$\begin{array}{c}\text { Ecological Environmental } \\
\text { Protection } \mathrm{B}_{61} \\
(0.3833)\end{array}$} & $\begin{array}{c}\text { Environmental Protection Monitoring and Protection } \\
\text { Measures } \mathrm{C}_{611}(0.3933) \\
\end{array}$ \\
\hline & & Conservation of Water and Soil $\mathrm{C}_{612}(0.3167)$ \\
\hline & & Destruction of Vegetation $\mathrm{C}_{613}(0.2100)$ \\
\hline & & Social Impact rate $\mathrm{C}_{614}(0.0800)$ \\
\hline & \multirow{3}{*}{$\begin{array}{l}\text { Resource Conservation } \mathrm{B}_{62} \\
(0.3833)\end{array}$} & Land Saving $\mathrm{C}_{621}(0.3333)$ \\
\hline & & Recycling and Recycling of Waste Materials $\mathrm{C}_{622}(0.3333)$ \\
\hline & & $\begin{array}{c}\text { Application of Water Saving and Timber Construction } \\
\text { Technology } \mathrm{C}_{623}(0.3333)\end{array}$ \\
\hline & \multirow{3}{*}{$\begin{array}{c}\text { Conserve Energy and } \\
\text { Reduce Emissions } \mathrm{B}_{63} \\
(0.2333)\end{array}$} & $\begin{array}{l}\text { Energy Saving Technology and Clean Energy Utilization } \\
\mathrm{C}_{631}(0.2708) \\
\end{array}$ \\
\hline & & $\begin{array}{c}\text { Elimination of Old Equipment with High Energy } \\
\text { Consumption } \mathrm{C}_{632}(0.2708)\end{array}$ \\
\hline & & $\begin{array}{l}\text { Reduction of Energy Consumption in Construction } \mathrm{C}_{633} \\
(0.4583)\end{array}$ \\
\hline \multirow{6}{*}{$\begin{array}{l}\text { Soft Power } A_{7} \\
\quad(0.0420)\end{array}$} & \multirow{2}{*}{$\begin{array}{l}\text { Quality Construction of } \\
\text { Controller } \mathrm{B}_{71}(0.2500)\end{array}$} & Post Assessment and Continuing Education $\mathrm{C}_{711}(0.6000)$ \\
\hline & & System of Excitation and Security $\mathrm{C}_{712}(0.4000)$ \\
\hline & \multirow{2}{*}{$\begin{array}{l}\text { Improving the Quality of } \\
\text { the Front-line Workers } B_{72} \\
(0.2500)\end{array}$} & System of Assessment and Training $\mathrm{C}_{721}(0.7500)$ \\
\hline & & System of Incentive and Guarantee $\mathrm{C}_{722}(0.2500)$ \\
\hline & \multirow{2}{*}{$\begin{array}{l}\text { Quality Engineering } \\
\text { Culture } \mathrm{B}_{73}(0.2500) \\
\end{array}$} & Propaganda Work $\mathrm{C}_{731}(0.3333)$ \\
\hline & & The Cultivation System of Quality Culture $\mathrm{C}_{732}(0.6667)$ \\
\hline
\end{tabular}




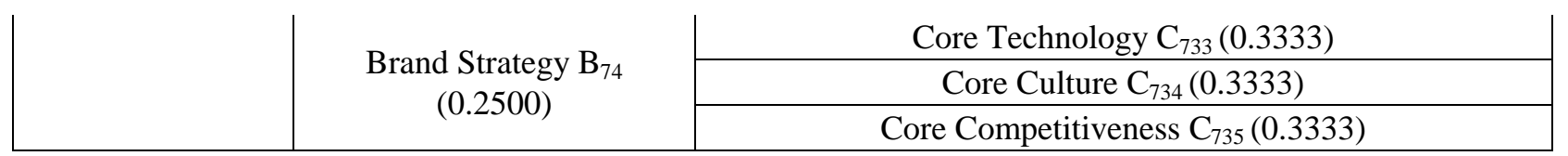

The weight of the index calculated by the analytic hierarchy process can be used to evaluate the actual situation of the specific project, which can truly reflect the quality of the construction.

\section{Conclusions}

The system completely covers all the contents of the quality of the highway water engineering. A standard system for building quality engineering has been formed. It sums up a unique, replicable and popularized management model. It puts forward the way to realize the operation which can be realized. The construction of the highway water transportation project according to the index system, could meet the requirements of "quality engineering" for highway transportation which formulated by the Ministry of Transportation.

\section{References}

[1] LI Qing-heng, GUO Chun-dong, CHEN Ai-zu, Research on quality evaluation mode of highway engineering, [J] Hebei Journal of Industrial Science and Technology 2006.03

[2] WANG Jin, JI Guang, MA Jun: Reserch on Evalution Index System and Methods for Highway with Low Carbon Emission [J] Highway 2014.07

[3] ZHU Hao-ran;CAI Hai-quan, in: Research on Evaluation Index System of Green Recycled Low-carbon Arterial Highways in Jiangsu Province, [J] Highway 2015.04

[4] Liu Jian;Zhou Hui, in: Research and application of evaluation index system of green low-carbond highways, [J] Shanxi Architecture, 2016.17

[5] Zhou Xiaohuan: An Evaluation Study on Expressways Based on Subjective and Objective Safety, [J] Journal of East China Jiaotong University 2012.06

[6] Hu Wan xin: Evaluation of Green and Low Carbon Highway Based on Interval Analytical Hierarchy Process, [J] Journal of East China Jiaotong University 2015.03

[7] Sun Li-hua: Study and Implementation of Expressway Traffic Conditions Evaluation considering Abnormal Data, [D] 2017.03 